\title{
Faculty Integration of Technology into Instruction and Students' Perceptions of Computer Technology to Improve Student Learning
}

\author{
Jared Keengwe \\ Department of Education, Muskingum College, OH, USA
}

¡keengwe@muskingum.edu

\section{Executive Summary}

There has been a remarkable improvement in access and rate of adoption of technology in higher education. Even so, reports indicate that faculty members are not integrating technology into instruction in ways that make a difference in student learning (Cuban, 2001; McCannon \& Crews, 2000). To help faculty make informed decisions on student learning, there is need for current knowledge of faculty integration practices. Therefore, the purpose of this study was to examine the nature of the relationship between faculty integration of technology into classroom instruction and students' perceptions of the effect of computer technology to improve their learning.

A sample of at least 800 undergraduate students at a participating medium-sized midwest public university was selected using a stratified random sampling technique. The researcher delivered and administered the surveys to the participating students and collected them after completion. $98 \%$ of the questionnaires were complete and retained for analysis. Two major statistical techniques were used to analyze data obtained in the study: a multiple regression and a Two-Way Analysis of Variance (ANOVA).

A statistically significant relationship was found between the three predictor variables and the criterion. The Two-Way ANOVA results indicated no interaction effect between gender and course levels, and students' perceptions of the effect of computer technology use to improve their learning. The main effects of gender and course levels were not statistically significant.

The results indicated that students lack computer skills in various computer applications that are necessary to support and enhance their learning experiences. Therefore, it can be suggested that students need to have direct instruction to efficiently use computer technology applications such as authoring and sophisticated hypermedia. These programs provide computer skills in advanced computer technology applications that will enable faculty members to expect more disciplinespecific computer-based projects such as developing a webquest in a web editor.

Keywords: Computer technology, computer proficiency, computer use, computer integration,

Material published as part of this publication, either on-line or in print, is copyrighted by the Informing Science Institute. Permission to make digital or paper copy of part or all of these works for personal or classroom use is granted without fee provided that the copies are not made or distributed for profit or commercial advantage AND that copies 1) bear this notice in full and 2) give the full citation on the first page. It is permissible to abstract these works so long as credit is given. To copy in all other cases or to republish or to post on a server or to redistribute to lists requires specific permission and payment of a fee. Contact Publisher@InformingScience.org to request redistribution permission. faculty

\section{Introduction}

Technology permeates all sectors of our lives. Educators have been under pressure to reform school through technology (Becker, 2001; Mehlinger, 1996; Sheingold \& Hadley, 1990). Over the past decade, educational stakeholders including administrators, parents, and 
even politicians have pushed towards the use and integration of educational technology in the classroom. Public and political support for technology use has generated billions of dollars toward increasing its availability to universities and corporate organizations. However, there is an alarming gap between technology's presence in higher academic institutions and its effective integration into classroom instruction (Bryant, 2000; Cuban, 2001).

Cuban (2001) argues that computers have been oversold by policy makers and advocates of technology use in education, but have not been effectively integrated into instruction. Further, knowledge of effective integration of technology into classroom instruction is not readily available. $\mathrm{Cu}-$ ban (2001) contends that remarkable changes have occurred in how students use computers in various places including their dormitories, libraries, and elsewhere on wired campuses, but a bleak side exists on how these tools are used for classroom instruction. While availability and access to instructional computer use have increased tremendously in higher education classrooms (Green, 2001), few faculty have demonstrated effective and efficient computer technology integration use in their classrooms (Cuban, 2001).

There is evidence that technology is changing the way instructors are teaching in their classes. For instance, in a study about the effectiveness of technology in schools, Sivin-Kachala and Bialo (2000) reported positive and consistent patterns when students were engaged in technology-rich environments. Even so, reports indicate that faculty members are not using technology in ways that make a difference in student learning (Anderson, 2000; Cuban, 2001; McCannon \& Crews, 2000). Regrettably, technology integration is lacking throughout the educational curriculum (International Society for Technology in Education, 2000).

The option for computer technology is neither a remedy for all education challenges (Tyack \& Cuban, 1995) nor a panacea for educational reform (Sandholtz, Ringstaff, \& Dwyer, 1997), but as a tool, it can be used to support learning. Even so, appropriate use of computer tools is primary to effective learning. Sandholtz, et al. (1997) contend that:

Technology is a catalyst for change in classroom processes because it provides a distinct departure, a change in context that suggests alternative ways of operating. It can drive a shift from a traditional instructional approach toward a more eclectic set of learning activities that include knowledge-building situations for students. (p. 47)

The success or failure of technology use depends more on "human and contextual factors than on hardware or software" (Valdez, McNabb, Foertsch, Anderson, Hawkes, \& Raack, 2000, p. 4.). Besides, the faculty beliefs about schooling are likely to influence their pedagogical styles as well as technology integration practices in the classroom (Sandholtz, Ringstaff, \& Dwyer, 2000). In addition, it is usually the factors that are personal and deeply ingrained, such as instructors' beliefs about the instruction process (Ertmer, 1999), and the value of computing in education (Kent $\&$ McNergney, 1999) that play a big role in the way faculty generally integrate technology tools into instruction.

For successful use of computers, educational stakeholders must shift their focus from just providing more computers in schools to investing in faculty. Fabry and Higgs (1997) state that:

If the integration of technology in the classroom in the next ten years is to look any different from the last ten, we must focus time, money, and resources in areas that can have the greatest impact for our students, our teachers. (p. 393)

\section{Purpose of Study}

There is a call for evidence regarding the justification of the massive investments into technology resources (Oppenheimer, 1997, 2003), especially as it relates to student learning. It cannot be assumed that once technology tools are available, faculty will necessarily embrace and integrate 
them into their classroom instruction. On the contrary, successful use of these tools to enhance student learning goes beyond the common task of just providing more machines in the classroom. Consequently, then, the challenge for researchers lies in the need to quantify the use of computer technology to support student learning (Oppenheimer, 2003; Roblyer \& Knezek, 2003; Strudler, 2003).

While various studies have explored the factors that enhance integration of technology into instruction as well as the barriers to effective technology integration, few studies are available on students' perceptions of computer technology use and the impact of these perceptions on their learning. In addition, while the public interest in the use and integration of computer technology in education is growing, research in this area is still in its infancy, especially that which focus on classroom instruction. Besides, rapid improvement in educational technologies exceeds the current knowledge of effective computer technology use in education (Allen, 2001) and implies the need for a study such as this.

The pressure to reform education through technology integration (Becker, 2001) and the emphasis on developing information literacy skills for students (Rockman, 2004) implies the need for an understanding of current computer technology integration practices to support student learning. Therefore, the purpose of this study was to determine the nature of the relationship between faculty integration of computer technology into classroom instruction and students' perceptions of the effect of computer technology to improve their learning.

The following research questions were investigated in the study:

1. What is the self-reported frequency of faculty integration of computer technology into classroom instruction?

2. To what extent does the self-reported frequency of faculty integration of computer technology, student's self-reported computer proficiency for personal activities, and students' self-reported computer proficiency for instructional activities predict their perceptions of the effect of computer technology to improve their learning?

3. Do differences exist across gender and course levels in the students' perceptions of the effect of computer technology to improve their learning?

\section{Significance of Study}

Educators have consistently made various assumptions about the relationships between technology integration and student learning. For instance, it is assumed that students who learn in classes where faculty members frequently integrate computer technology into instruction are likely to exhibit positive perceptions about computer technology use to enhance their learning. While certain assumptions made about the relationships between computer technology tools and student learning may be true, this study intended to provide data to support or question that which is assumed.

Secondly, many universities across the nation are experiencing rapid technological changes, continuous shifts in the learning environments, and a new generation of students exhibiting varied computer technology skills. This trend calls for current understanding of faculty computer technology integration practices. Specifically, this study sought to provide evidence about the frequency of faculty integration of computer use into instruction and its relationship to student learning.

Finally, examining the interaction of variables such as students' course levels, gender, and student learning could help faculty to identify course levels as well as type of gender that needs more time and technology resources to support learning. Further, evidence from this study could help 
faculty to establish specific ways to motivate all students (male or female) or target specific course levels where students report that computer technology integration does not advance their learning.

\section{Method}

\section{Research Design}

The study utilized a survey for data collection. A survey is an attempt to collect data from members of a population with respect to one or more variables (Gay \& Airasian, 2003). The goal of a survey is to gain specific information about a representative sample of a particular group; a selfreport measure is a strong method to provide great insight on an individual's perception. Closeended surveys were administered to a sample of a sample of research participants and collected by the researcher after completion.

\section{Identification of Variables}

Three predictor variables were explored in this study: faculty integration of computer technology, student's self-reported computer proficiency for personal activities, and students' self-reported computer proficiency for instructional activities. There were two independent variables in this study: gender and course level. The only dependent variable was the students' perceptions of the effect of computer technology to improve their learning.

\section{Participants}

The sample for this study was derived from undergraduate students enrolled in a medium-sized Midwest public university. A medium sized university was also chosen due to its ability to attract diverse faculty and student body characteristic of most medium sized North American colleges and universities. To have a more representative sample of the population in the participating university, different courses were selected across the five colleges. A list of all courses offered during a fall semester at the participating institution was stratified by collegiate level, yielding four strata: course levels 100, 200, 300, and 400.

Random sampling was then used to select two courses from each of the 4 levels across the five colleges. The researcher focused on courses with 20 students and more. Given that there were 5 colleges and 8 courses drawn from each college at each level, a total of 40 courses, and at least 800 participants were expected to be part of the study. The use of this sampling procedure was based on the following criteria: (a) The total number of subjects surveyed should not be unwieldy; a manageable sample size would be easy to collect, analyze and interpret; (b) Equal representation of the five colleges; (c) Equal representation of the 4 possible course levels; and (d) Easy accessibility of students enrolled in different majors.

\section{Instrument}

The researcher employed a survey method to collect, tabulate and analyze the data. The Computer Technology Integration (CTI) Survey was designed to measure faculty integration of computer technology into classroom instruction and students' perceptions of the effect of computer technology use to improve their learning. The 55-item CTI survey consisted of 5 major sections. The first section was designed to include questions on demographic information (Question 1-3). The second and third section consisted of 10 items in each section assessing the degree to which students felt competent in performing various computer applications. The computer proficiency skills for personal as well as instructional activities items were measured on a scale of 1 to 3 . Score 1 being not at all competent, 2 being somewhat competent and 3 very competent. The stu- 
dents' computer proficiency score for personal and instructional activities was established by summing up all the scores of the items included in the second and third section respectively. In the fourth section, respondents were required to respond to items on a Likert-type scale from 1 to 4 (1-3 times Per Week/Very often = 4; Often/ 1-3 times Per Month = 3; Sometimes/Few times per Semester $=2$, and Never, $\mathrm{N}=1$ ) regarding the frequency with which their instructor integrated computer technology during classroom instruction. The students' perceptions of faculty computer technology integration score was established by summing up all the scores of the items included in the fourth section. In the fifth section, respondents were required to respond to items on a Likert-type scale from 1 to 4 (Strongly Disagree, $\mathrm{SD}=4$, Disagree, $\mathrm{D}=3$; Agree, $\mathrm{A}=2$, and Strongly Agree, $\mathrm{SA}=1$ ) regarding students' perceptions of the effect of computer technology use on their learning. The students' perceptions of the effect of computer technology to improve their learning score was established by summing up all the scores of the items in the fifth section and then dividing the total score by the number of the items to establish the mean score that was used for statistical analysis.

An initial draft of the questionnaire that contained items to be included in the survey was reviewed by three faculty members knowledgeable in the field of education technology. Additionally, these faculty members have terminal degrees in the field of instructional technology. Based on their specific comments and informed feedback regarding areas that required further clarification, the survey format was restructured, and several items in the survey were revised for improved clarity.

An initial pilot study was conducted using a convenience sample of 20 students enrolled in one course at the participating university. Based on the feedback obtained from the pilot study, the instrument was revised. The revised version of the survey was administered to a different course in a second pilot study. The results of the second pilot study were hand tabulated by the researcher to establish preliminary results, check the appropriateness of standard measures, determine potential areas of concern, and to identify questions that would require further clarification.

A coefficient of .90 indicates a highly reliable instrument but coefficients ranging from .70 to .94 are acceptable for most instruments (McMillan \& Schumacher, 1997). All the five sections of the Computer Technology Integration (CTI) surveys had a Cronbach alpha value ranging from .73 to .83 during the pilot testing of the CTI to a convenience sample of 20 students and were therefore found to be within the acceptable range to be used for the actual study. After data collection, separate Cronbach's reliability coefficients were calculated for the sample respondents $(N=837)$. A summary of the Cronbach alpha scores for the pilot and the sample respondents is provided in Table 1.

Table 1: Cronbach Alpha scores for the survey sections

\begin{tabular}{lccc}
\multicolumn{1}{c}{ Section } & \# of Items & Pilot alpha & Sample alpha \\
Personal Proficiency & 10 & .82 & .77 \\
Instructional Proficiency & 10 & .81 & .84 \\
Faculty Integration & 12 & .71 & .78 \\
Student Perceptions & 20 & .73 & .73 \\
\hline
\end{tabular}

\section{Procedures}

Using the university's website, the complete list of courses was stratified by course levels yielding four strata: course levels 100, 200, 300 and 400. The researcher used randomization of the four course levels until an acceptable total sample of 40 courses was reached. The researcher con- 
tacted the professors teaching the selected courses. After permission from the professors, the researcher visited the different classrooms to administer the survey.

A Consent Form explaining the purpose of the study and soliciting the students' willingness to fill the survey, and the survey questionnaires were hand-delivered and administered to the participating students in the respective courses. Student and faculty names were not identified anywhere on the survey for confidentiality purposes. The students handed the surveys back to the researcher after completing them in about 10 minutes. The data were coded and prepared for analysis using the Statistical Package for Research Software Program (SPSS). Both descriptive and inferential statistics were used to evaluate and report the results. Frequencies, Multiple Regression analysis and Analysis of Variance (ANOVA) techniques were used to answer questions 1, 2, and 3, respectively.

\section{Results}

\section{Computer Proficiency for Personal Activities}

For personal activities, most participants reported to be very competent in applications such as the Internet and WWW (92.5\%); moderately competent in applications such as electronic files attachments (73.1\%) and least competent in using web authoring tools, and using Hyperstudio, HyperCard, or other multimedia authoring application (13.9\% and 3.9\%, respectively). Table 2 summarizes the personal computer skills responses for the 837 students scored across the three scales. The list of computer applications was then rank ordered based on student responses.

Table2: Student self-rating of computer proficiency for personal activities

\begin{tabular}{lccc} 
Computer Tool/Application & 1 & 2 & 3 \\
\hline 1. Internet and WWW for personal activities. & $.4 \%$ & $7.2 \%$ & $92.5 \%$ \\
2. Electronic mail (e-mail application). & $.7 \%$ & $9.1 \%$ & $90.2 \%$ \\
3. Word processing (MS Word). & $.5 \%$ & $11.9 \%$ & $87.6 \%$ \\
4. Operating system (e.g. Windows, Mac, etc). & $.5 \%$ & $11.3 \%$ & $86.3 \%$ \\
5. Electronic files attachment for personal activities. & $2.7 \%$ & $24.1 \%$ & $73.1 \%$ \\
6. Computers for playing computer games, Videos, etc. & $6.0 \%$ & $28.4 \%$ & $65.6 \%$ \\
7. Internet chat rooms for personal activities. & $11.9 \%$ & $39.2 \%$ & $48.9 \%$ \\
8. Spreadsheet to record/organize personal activities. & $9.6 \%$ & $50.9 \%$ & $39.5 \%$ \\
9. Web authoring tools to build personal Web pages. & $45.6 \%$ & $40.5 \%$ & $13.9 \%$ \\
10. Hyperstudio, etc for personal activities. & $72.9 \%$ & $23.2 \%$ & $3.9 \%$
\end{tabular}

${ }^{*}$ Note: Score $1=$ not at all competent, 2 = somewhat competent, and 3 = very competent.

\section{Computer Proficiency for Instructional Activities}

For instructional activities, most participants reported to be very competent in Internet and WWW $(81.1 \%)$, electronic email $(80.0 \%)$ and least competent in using web authoring tools to build course-related Web pages (13.7\%). In other words, the participants' responses indicated a high level of computer proficiency in using word processing, using software, using electronic mail, using electronic files, using the Internet and the World Wide Web, for both personal and instructional activities. 


\section{Research Question One}

What is the self-reported frequency of faculty integration of computer technology into classroom instruction?

The participants reported that their faculty often used productivity tools, multimedia presentation, web browsers, computer projection devices, course management tools and email $(\mathrm{M}=2.73,2.82$, $2.87,2.68,2.90$, and 2.9 , respectively) for instruction. The participants reported that their faculty rarely used web publishing, content specific software, imaging devices, and discipline devices such as calculators $(\mathrm{M}=1.59,1.89,1.88,1.66$, and 2.08 , respectively). Most participants reported that faculty never used desktop video conferencing $(\mathrm{M}=1.43)$ for instruction. The participants reported that their faculty often used course management tools $(40.9 \%)$ and rarely used web publishing tools (3.8\%) for classroom instruction. Table 3 summarizes the results on 837 student response scored across the four scales. The list of applications was rank ordered to indicate the most frequently used computer tool.

Table 3: Student perceptions of faculty integration of technology into instruction

$\begin{array}{lcccc}\text { Computer Tool/Application } & 1 * & 2 & 3 & 4 \\ \text { 1. Using course management tools } & 15.7 \% & 19.1 \% & 24.4 \% & 40.9 \% \\ \text { 2. Web browsers. } & 14.5 \% & 24.7 \% & 20.2 \% & 40.6 \% \\ \text { 3. Email for feedback/communication. } & 10.3 \% & 24.9 \% & 28.9 \% & 36.0 \% \\ \text { 4. Computer projection device. } & 15.8 \% & 33.0 \% & 19.0 \% & 32.3 \% \\ \text { 5. Multimedia presentation tools. } & 9.0 \% & 31.4 \% & 28.1 \% & 31.5 \% \\ \text { 6. Productivity tools. } & 13.4 \% & 30.5 \% & 26.0 \% & 30.1 \% \\ \text { 7. Teaching in a multimedia classroom. } & 38.9 \% & 29.2 \% & 16.7 \% & 15.2 \% \\ \text { 8. Imaging Devices. } & 46.8 \% & 27.4 \% & 16.6 \% & 9.2 \% \\ \text { 9. Discipline Devices. } & 57.2 \% & 26.6 \% & 9.1 \% & 7.0 \% \\ \text { 10. Content specific Software/ CD-ROM. } & 37.9 \% & 42.2 \% & 13.5 \% & 6.5 \% \\ \text { 11. Desktop video conferencing/ chat sessions. } & 71.1 \% & 19.2 \% & 4.9 \% & 4.8 \% \\ \text { 12. Web publishing/authoring tools. } & 56.6 \% & 31.4 \% & 8.1 \% & 3.8 \%\end{array}$

${ }^{*}$ Note: Score $1=$ Never, $2=$ Sometimes/Few times per Semester, $3=$ Often/ 1 - 3 times per Month=3; 4 = Very often $/ 1-3$ times Per Week.

\section{Research Question Two}

To what extent does the self-reported frequency of faculty integration of computer technology, student's self-reported computer proficiency for personal activities, and students' self-reported computer proficiency for instructional activities predict their perceptions of the effect of computer technology to improve their learning?

A simultaneous regression analysis was conducted with all three predictor variables. This analysis produced a significant model with the value of $\mathrm{R}^{2}=0.039$. In other words, the percentage of the total variance in criterion that was shared with the set of the predictor variables was $3.9 \%$. This was significant at the 0.001 level.

The standardized partial regression coefficient for faculty total was $-.204, t=-5.663$, and $p=$ .001 . Therefore, the faculty total was a significant predictor of the student's perceptions of computer use to improve their learning (after controlling for the instructional and personal total). The standardized partial regression coefficient for instruction total was $-.013, t=-.237$, and $p=.812$. Therefore, the instructional total was not a significant predictor of the student's perceptions of 
computer use to improve their learning (after controlling for the faculty total and personal total). The standardized partial regression coefficient for personal total was .084, $t=1.504$, and $p=$ .133. Therefore, the personal total was not a significant predictor of the student's perceptions of computer use to improve their learning (after controlling for the faculty total and instructional total). A summary of the results of the tests is provided in Table 4.

Table 4: Summary of multiple regression analyses of predictors and criterion

\begin{tabular}{lccccc} 
Variable & $\mathrm{B}$ & $\mathrm{SE} \mathrm{B}$ & $\ddot{\mathrm{y}}$ & $t$ & $p$ \\
\hline Faculty Total & -.190 & .034 & -.204 & -5.663 & .001 \\
Instruction total - & .021 & .090 & -.013 & -.237 & .812 \\
Personal total & .168 & .112 & .084 & 1.504 & .133
\end{tabular}

\section{Research Question Three}

Do differences exist across gender and course levels in the students' perceptions of the effect of computer technology to improve their learning?

Differences between gender and course levels, and students' perceptions of the effect of computer technology use to improve their learning were tested using a Two-Way ANOVA. The test showed no significant main effect for the gender factor, $\mathrm{F}(1,829)=.664, p>.05$; no significant main effect for the course level factor, $\mathrm{F}(3,829)=.511, p>.05$; and no significant interaction between gender and course level, $\mathrm{F}(3,829)=1.627, p>$. 05 .

No interaction was found between gender and course levels and students' perceptions of the effect of computer technology use to improve their learning. The main effects of gender and course levels were not statistically significant. Therefore the lack of significant interaction between gender and course level indicates than gender and course levels do not significantly impact students' perceptions of computer use to improve their learning. The results are reported in Table 5.

Table 5: Results of Two-Way ANOVA analysis for gender and course levels

\begin{tabular}{|c|c|c|c|c|c|}
\hline Source & & & MS & $\mathrm{F}$ & $\mathrm{P}$ \\
\hline Corrected & 7 & 244.364 & 34.909 & .984 & .44 \\
\hline Gender & 1 & 23.546 & 23.546 & .664 & .415 \\
\hline Course Level & 3 & 54.350 & 18.117 & .511 & .675 \\
\hline Gender*Course & 3 & 173.062 & 57.687 & 1.627 & .182 \\
\hline Error & 829 & 29401.894 & 35.467 & & \\
\hline
\end{tabular}

$* p<.05$

\section{Discussion}

The study provided evidence that faculty integrated the following computer technologies - productivity tools, multimedia presentation tools, web browsers, computer projection devices, course management tools and email - often into their classroom instruction. Further, the study provided evidence that faculty seldom integrated web publishing, content specific software, imaging devices, discipline devices, and seldom taught in multimedia classrooms. The results suggest that desktop video conferencing were almost never integrated into classroom instruction to support student learning. 
The study provided evidence to suggest that a relationship exists between students' personal computer proficiency and students' perceptions of the effect of computer technology to improve their learning. Results also suggest that students expressed high computer proficiency or competency in some technology applications such as email, and the Internet, but they lacked depth in specific areas of their computer skill repertoire such as hypermedia and authoring tools.

The results of the study indicated a relationship exists between students' personal computer proficiency and students' instructional computer proficiency. The regression analyses showed a positive correlation between students' personal computer proficiency and instructional computer proficiency.

No differences were found in males and females and course levels and the students' perceptions of computer use to improve their learning across gender. A lack of significant interaction between gender and course level suggests that the effect of gender and course levels does not affect the student's perceptions of how much computer technology improved their learning. In addition, based on this finding, it suggests that gender disparities in the classroom, if existent, may be minimal.

Educational technology has changed over time; technology is quickly changing with notebooks starting to replace the personal computers in many classrooms across the nation (Ellin, 2000). Further, there is a common trend toward improving student learning through a seamless integration of technology through all the facets of educational system. Even so, the results from this study indicate that students are not highly proficient in higher-end computer applications that could enhance their learning experiences. Therefore, evidence suggests that students need to have direct instruction to efficiently use computer tools such as sophisticated hypermedia.

The results of the study indicated a relationship between faculty integration of computer technology into classroom instruction and students' perceptions of the effect of computer technology to improve their learning. However, the standardized partial regression coefficient for faculty integration was negative. This finding could be attributed to factors that include social, contextual, and personal influences. For instance, due to the digital divide among college students, students might perceive the value of computing for improved learning differently and fail to understand the role of technology in transforming their courses (Beisser, Kurth, \& Reinhart, 1997). Instructional and contextual factors such as student comfort levels, and experiences could affect students' perceptions of technology use to improve their learning.

\section{Limitations}

This study was designed to focus on undergraduate students drawn from five colleges at a participating medium-sized Midwest public university. It is possible that results might not generalize to other types of institutions, such as large or private institutions.

Second, the study used a self-reported questionnaire survey which is limited in nature by the accuracy of the participant's responses (Kerlinger \& Lee, 2000). Although the researcher took methodological steps to facilitate accurate reporting such as confidentiality and voluntary participation, these procedures might have not ruled out the biases associated with self-report measures, including social desirability. Despite limitations of the instrument used, including socially desirable answers, a self-report measure is a strong method to provide great insight on an individual's perception.

\section{Summary}

Universities across the nation are experiencing rapid technological changes, continuous shifts in the learning environments, and a generation of students exhibiting diverse computer proficiency 
skills. Yet in many locations, the rapid improvement in these technologies exceeds the current knowledge of effective technology use (Allen, 2001). Therefore, this study provided baseline data to identify current faculty computer integration practices. These data can guide institutions to examine their current technology practices and provide grounds to make sound technology-related decisions that can maximize student learning.

Educators have also made various assumptions about the relationships between computer technology integration, content instruction, and student learning. For instance, faculty may assume that students learning in modern technology era are highly competent in general computer skills and are more prepared to learn with technology as opposed to the previous generations of students. Evidence from this study provides a data set to question such thinking. Instead, there is evidence suggesting a need for direct instruction in the use of sophisticated software programs. Further, the distinction between personal and course-related use illustrates the need for faculty to create bridges between personal and instructional use of technology for improved student learning.

Technology has the potential for changing the way teachers teach and students learn (Thompson, Schmidt, \& Davis, 2003), but research indicates that educators are less likely to use computers than other professions (Hanushek, 1998). In addition, teachers play a major role in how successful technology will be in education (Yildirim \& Kiraz, 1999). Thus, if we want to maximize student learning, we should invest time, money, and technology resources in areas that can have the greatest impact for our students such as the faculty (Fabry \& Higgs, 1997).

\section{References}

Allen, R. (Fall 2001). Technology and learning: How schools map routes to technology's promised land. ASCD Curriculum Update, 1-3, 6-8.

Anderson, M. A. (2000). Staff development: Your most important role. Multimedia Schools, 7(1 Jan. /Feb.), 24-27.

Becker, H.J. (2001). How are teachers using computers in instruction? Paper presented at the 2001 meeting of the American Educational Research Association. Retrieved May 25, 2005, from http://www.crito.uci.edu/tlc/FINDINGS/special3/

Bessier, S., Kurth, J., \& Reinhart, P. (1997). The teacher as a learner: An undergraduate students and faculty mentorship success. In D. Willis, B. Robin, J. Willis, J. Price, \& S. McNeil (Eds.), Technology and teacher training annual, 322-326. Charlottesville, VA. Association for the Advancement of Computing in Education.

Bryant, A. L. (2000). Investment in education and technology: The key to preparing for the digital age. In Technos: Quarterly for Education and Technology, Winter. Retrieved March, 20, 2005, from http://www.findarticles.com/cf dls/m0HKV/4 9/68951437/p1/article.jhtml

Cuban, L. (2001). Oversold and underused: Computers in the classroom. Cambridge, MA: Harvard University Press.

Ellin, M. (2000, May 1). A laptop for every kid. Time, 155(18), 57.

Ertmer, P. (1999). Addressing first-and second-order barriers to change: Strategies for technology integration. Educational Technology Research and Development, 47(4), 47-61.

Fabry, D., \& Higgs, J. (1997). Barriers to the effective use of technology in education. Journal of Educational Computing, 17(4), 385-395.

Gay, L. R., \& Airasian, P. (2003). Educational research: Competencies for analysis and applications (7th ed.). Upper Saddle River, NJ: Pearson Education. 
Green, K. C. (2001). The 2001 National Survey of Information Technology in US Higher Education. The campus computing project. Retrieved April 24, 2005, from http://www.campuscomputing.net/summaries/2001/

Hanushek, E. A. (1998). Outcomes, incentives, and beliefs: Reflections on analysis of the economics of schools. Educational Evaluation and Policy Analysis, 19(4), 301-308.

International Society for Technology in Education (ISTE). (2000). National Educational Technology Standards (NETS) for teachers. Retrieved May 25, 2005 from http://cnets.iste.org/teachers/

Kent, T. W., \& McNergney, R.F. (1999). Will technology really change education? Thousand Oaks, CA: Corwin Press.

Kerlinger, F. N., \& Lee, H. B. (2000). Foundations of behavioral research (4th ed.). Fort Worth, TX: Harcourt.

McCannon, M., \& Crews, T. B. (2000). Assessing the technology training needs of elementary school teachers. Journal of Technology and Teacher Education, 8(2), 111-21.

McMillan, J. H., \& Schumacher, S. (1997). Research in education: A conceptual introduction (4th ed.). Don Mills, ON: Longman.

Mehlinger, H. D. (1996). School reform in the information age. Phi Delta Kappan, 400-407.

Oppenheimer, T. (1997). The computer delusion. The Atlantic Monthly, 280(1), 45-62.

Oppenheimer, T. (2003). The flickering mind: The false promise of technology in the classroom and how learning can be saved. New York: Random House.

Roblyer, M. D., \& Knezek, G. A. (2003). New millennium research for educational technology: A call for a national research agenda. Journal of Research on Technology in Education, 36(1), 60-71.

Rockman, I. F. (2004). Integrating information literacy into the higher education curriculum: Practical models for transformation. San Francisco, CA: Jossey-Bass.

Sandholtz, J. H., Ringstaff, C., \& Dwyer, D. (1997). Teaching with technology: Creating student-centered classroom. New York: Teachers College Press.

Sandholtz, J. H., Ringstaff, C., \& Dwyer, D.C. (2000). The evolution of instruction in technology-rich classrooms. In R. D. Pea (Ed.), Technology and learning. San Francisco, CA: Jossey-Bass.

Sheingold, K., \& Hadley, M. (1990). Accomplished teachers: Integrating computers into classroom practices. New York: NY. Bank Street College of Education, Center for Technology in Education.

Sivin-Kachala, J., \& Bialo, E. (2000). 2000 research report on the effectiveness of technology in schools (7th ed.). Washington, DC: Software and Information Industry Association.

Strudler, N. (2003). Answering the call: A response to Roblyer and Knezek. Journal of Research on Technology in Education, 36(1), 72-76.

Thompson, A.D., Schmidt, D.A., \& Davis, N.E. (2003). Technology collaborative for simultaneous renewal in teacher education. Educational Technology, Research and Development, 51(1), 73-89.

Tyack, D., \& Cuban, L. (1995). Tinkering toward utopia: A century of public school reform. Boston, MA: Harvard University Press.

Valdez, G., M. McNabb, M., Foertsch, M., Anderson, M., Hawkes, M., \& Raack, L. (2000). Computerbased technology and learning: Evolving uses and expectations. Retrieved June 25, 2005, from http://www.ncrel.org/tplan/cbtl/toc.htm

Yildirim, S., \& Kiraz, E. (1999). Obstacles to integration of on-line communication tools into preservice teacher education. Journal of Computing in Teacher Education, 15(3), 23-28. 


\section{Biography}

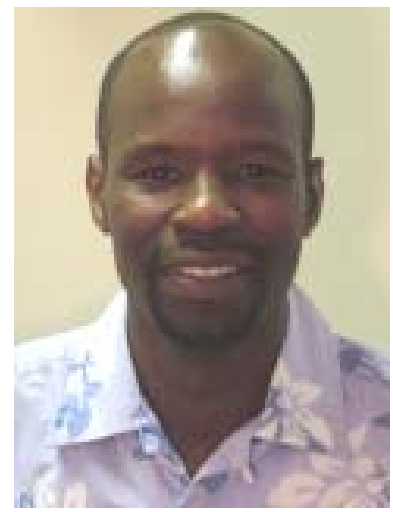

Jared Keengwe is Assistant Professor of Education at Muskingum College. He previously taught at Indiana State University, IN, USA where he also received his Ph.D. in Curriculum and Instruction (Educational Technology). He is cited in the 60th Edition (2006) of who is who in America as well as the 7th Edition (2006-2007) of who is who in American Education. His research and writing focus on pedagogical uses of computer tools, and integration of specific computer tools into actual classroom instruction to support meaningful learning. 